Title

Older Teen Attitudes Towards Birth Control Access in Pharmacies: A Qualitative Study

\title{
Authors
}

Tracey A. Wilkinson, MD, MPH ${ }^{1}$

Courtney Miller, $\mathrm{BA}^{2}$

Samantha Rafie, $\mathrm{PhD}^{3}$

Sharon Cohen Landau, $\mathrm{MPH}^{4}$

Sally Rafie, PharmD ${ }^{2,5}$

${ }^{1}$ Indiana University School of Medicine, Department of Pediatrics, Indianapolis, IN

${ }^{2}$ University of California San Diego, Skaggs School of Pharmacy and Pharmaceutical

Sciences, San Diego, CA

${ }^{3}$ Feinberg Medical Group, Palo Alto, CA

${ }^{4}$ Los Angeles, CA

${ }^{5}$ University of California San Diego Health, San Diego, CA

Corresponding Author

Sally Rafie, PharmD

Pharmacist Specialist

UC San Diego Health

200 W. Arbor Dr. \#8765

San Diego, CA 92103

(619) 543-3601 (phone)

(619) 543-5829 (fax)

srafie@ucsd.edu

Abstract Word Count: 250

Manuscript Word Count: 2709

Financial Disclosures

None of the authors have any financial disclosures.

Conflicts of Interest

None of the authors have any conflicts of interest to disclose.

This is the author's manuscript of the article published in final edited form as:

Wilkinson, T. A., Miller, C., Rafie, S., Landau, S. C., \& Rafie, S. (2017). Older Teen Attitudes Towards Birth Control Access in Pharmacies: A Qualitative Study. Contraception. https://doi.org/10.1016/j.contraception.2017.11.008 


\section{ABSTRACT \\ Older Teen Attitudes Towards Birth Control Access in Pharmacies: A Qualitative Study}

Tracey A. Wilkinson, MD, MPH, Courtney Miller, BA, Samantha Rafie, PhD, Sharon Cohen Landau, MPH, Sally Rafie, PharmD

Objectives: To examine adolescent attitudes toward accessing contraception through a new pharmacist prescribing model in the State of California.

Study Design: In-depth telephone interviews were conducted in summer 2015 with 30 females ages 18 to 19 in California. Participants were recruited using a social media advertisement. Semi-structured interviews utilized open-ended questions to understand teens' experiences with pharmacies, experiences obtaining contraception at pharmacies, and views on pharmacist prescribing of contraception. Responses were transcribed and qualitatively analyzed using an independent-coder method to identify salient themes.

Results: Participants were ethnically diverse and primarily living in suburban areas. All participants had completed high school and many had completed one year of college. Nearly all participants were supportive of California's new law allowing pharmacist prescribing of contraception. Thematic analyses revealed that while participants were satisfied with traditional service providers and valued those relationships, they appreciated the benefit of increased access and convenience of going directly to a pharmacy. Participants expected increased access to contraception in pharmacies would lead to both personal and societal benefits. They expressed concerns regarding parental involvement, as well as confidentiality in the pharmacy environment and with insurance disclosures.

Conclusion: Older teens in California are very supportive of pharmacies and pharmacists as direct access points for contraception, but confidentiality concerns were noted. Policy makers and pharmacies can incorporate study findings when designing policies, services, and physical pharmacy spaces to better serve teens. Further research is warranted after pharmacies implement this new service to assess teen utilization and satisfaction as well as outcomes.

Keywords: direct pharmacy access; hormonal contraception; adolescents; pharmacist prescribing

Abbreviations: None 


\section{Implication Statement:}

Several states recently passed legislation enabling pharmacists to prescribe contraception and other states are considering similar legislation. Older adolescents are interested in this additional method of contraceptive access and understanding their perspectives can help guide implementation by states and in individual pharmacies.

\subsection{Introduction}

Adolescents experience unintended pregnancy at a rate higher than the general population, which can be attributed in part to challenges in accessing hormonal contraception.[1] In fact, the recent decline in teenage pregnancy rates in the United States has been almost exclusively credited to increased use of contraceptives (both hormonal and non-hormonal), but teenage pregnancy rates remain higher than average.[2] Considerable obstacles remain for adolescents wishing to access contraception.

Teenagers face a number of potential barriers to obtaining hormonal contraception with traditional clinician prescribing and subsequent filling of a prescription at a pharmacy. Barriers such as obtaining a timely appointment, limited office hours, transportation, cost, and concerns about confidentiality or pelvic exams have been described. [3-9]

Pharmacist prescribing of non-long acting reversible contraception may be one strategy to help alleviate some of the barriers that adolescents face. If large numbers of community pharmacies become involved in providing this service, they may reduce barriers that exist at doctor's offices given they are more accessible than many doctor's offices or clinics simply because of the number of pharmacies, proximity to patients' 
homes, and their expanded hours of operation. Pharmacist prescribing protocols involve patients completing a screening form that will identify category 3 and 4 conditions as defined by the evidence-based US Medical Eligibility Criteria for Contraceptive Use[10], blood pressure measurement, counseling on various methods, and pharmacist prescribing of contraception. Six states (California, Oregon, Colorado, Hawaii, Maryland and New Mexico), have recently passed legislation or have regulations in place to permit pharmacist prescribing of contraception, although California is the only state to allow those under 18 years old to utilize this program without proof of prior prescription.[11-13] Currently, in California, trained pharmacists may prescribe birth control pills, patch, ring or injection. There is a requirement to refer as needed and notify the patient's primary care physician about any prescriptions for contraception that has been written. There may be a visit fee (generally up $\$ 50$ ) that is paid out-of-pocket by the patient. Legislation has been passed for Medicaid coverage of this fee, but at the time of publication, it has yet to be implemented. Pharmacists interested in providing contraception services must complete the required training in pharmacy school or a minimum one-hour continuing education program.

Previous literature examined the interest in and support for this access model from perspectives of providers, pharmacists, pharmacy students, and consumers. [1419] Overall, the literature shows that there is support for this additional model of access amongst not only providers and pharmacists, but also women who would utilize this option. While the data support this access model, adolescents' preferences for utilizing pharmacist-initiated prescription birth control are not yet known. 
The purpose of this study was to describe adolescent attitudes toward access to contraception using the traditional prescription model, as well as their attitudes and interests in pharmacist prescribing of non-long acting reversible contraception before it was implemented in California.

\subsection{Materials and Methods}

Eligible participants were English-speaking females, aged 18 to 19 years old, living in California between July and September 2015. Participants were recruited via social media advertisements on Facebook which targeted potential participants based on their age and location. Eligibility was determined with an online screening survey followed by final eligibility verification conducted via self-report at the start of the interview. Given that participants were recruited through online social media, the aforementioned procedures were utilized to ensure valid sampling.

The social media advertisement was shown a total of 44,994 times, and 992 (2.2\%) individuals clicked on the advertisement. Of those, $286(28.9 \%)$ initiated the recruitment survey and 104 (10.4\%) completed it, of which 36 respondents did not meet eligibility requirements. The final sample consisted of 30 randomly selected participants and was inferred from similar qualitative studies to be sufficient to reach thematic saturation.

The interview guide was developed by study team members, which included experts in the areas of women's health and qualitative research methods. Questions covered topics regarding previous experiences at pharmacies and participants' awareness and opinions about pharmacist prescribing. All study materials were reviewed to ensure a sixth-grade reading level and targeted to participants' age. 
Interviews took approximately thirty minutes to complete and participants were compensated for their time.

A single investigator conducted in-depth telephone interviews using the standardized interview guide consisting of 24 open-ended questions aimed at generating qualitative discussion. Interviews were recorded with permission and later transcribed and proofread. After initial review of the transcripts, emerging themes were identified and study investigators developed a preliminary coding structure. Coding procedures were reviewed with all team members to increase inter-rater reliability. Two investigators then independently coded each interview and discrepancies were reconciled through team discussion. The study protocol was approved by the University of California San Diego Institutional Review Board.

\subsection{Results}

Participant characteristics are summarized in Table 1. There was equal participation by 18 and 19 year olds. A large proportion of participants were White $(37 \%)$ or Hispanic $(30 \%)$, and lived in suburban areas (63\%). All participants completed high school and the majority completed at least one year of college $(60 \%)$.

A vast majority of participants had experience with using hormonal contraception prior to the interview (93\%) and were supportive of pharmacist prescribing (97\%). Following analyses of the interviews, five major themes emerged that included satisfaction and challenges with the traditional care model, discussion regarding the pharmacy environment, birth control service preferences, resulting personal benefits and concerns, as well as social impact. Table 2 provides additional quotes from participants that captured these themes. 


\subsubsection{Satisfaction and Challenges with Traditional Care Model}

Older adolescents expressed satisfaction and challenges with the traditional care model that involves an office visit with a traditional provider, receiving counseling, and a subsequent prescription for contraception. Receiving care in a traditional setting created a sense of trust to the information provided as well as offering a setting that felt safe. In addition, adolescents valued the relationship with their current provider that enabled conversations regarding sensitive topics. Together, these sub-themes expressed a satisfaction with their current providers and the traditional care model.

"You form a bond with your doctor because you see them pretty often and you...know that there's the doctor-patient confidentiality thing so they're not going to tell anyone, and you're in a closed room."

However, there were noted barriers to seeing a traditional provider that included waiting times, convenience and cost.

"We don't always have time and going to the doctors is expensive. It isn't cheap." These were often described through experiences of having to return for refills or a new prescription and the cost was not only monetary, but also in time.

\subsubsection{Pharmacy Environment}

Older adolescents discussed various aspects of a pharmacy setting and identified important factors for consideration. Study participants highlighted the logistical concerns to receiving contraception directly at a pharmacy and noted the potential challenge of having a private conversation.

"It's kind of a very public area and I feel like that's sort of a more private conversation. So it would be just a little bit weird having that over the counter." 
Additionally, participants expressed the importance of pharmacies communicating their ability and interest in serving adolescents. For example, displaying images that included adolescents and messaging that is inviting.

Older adolescents felt that pharmacists were knowledgeable and a trusted source for health information including contraceptive options. Adolescents stressed that given the sensitive nature of their sexual health needs, it was also important that pharmacists, the pharmacy staff, and the pharmacy setting itself be approachable and aware of the potential stigma around adolescent sexual health.

In addition, the accessibility and convenience of obtaining contraception at a pharmacy directly was described as a benefit for the time saved due to the proximity and numerous options in the area.

"It's just less time consuming and it's just easier to get to because a lot of people don't have access to the clinics or to the doctor's office. So being able to walk into a pharmacy and having the pharmacist being able to help you with that is going to be a lot more of a convenience."

\subsubsection{Birth Control Service Preferences}

Certain preferences regarding counseling, personalization, cost, safety and confidentiality were expressed when discussing contraceptive services. Participants identified the importance of receiving education and counseling regarding various methods while also expressing the need for pharmacies to have the physical space to have these conversations privately.

"They should have a room and then have all the different methods so we could see them and be like okay. And they should have a lot of pamphlets and stuff like that. Almost like the doctor's office but to a point where it's just confidential." 
Older adolescents acknowledged that contraception choices are different for each person, thus recognizing the importance of information and options tailored to the individual instead of standard information for all customers.

The cost of contraception through a pharmacist prescribing model was a concern to teens and whether their out of pocket costs would change with this new model was noted and described as a potential barrier by some respondents if they had to pay the day the services were received.

Because pharmacist prescribing would still utilize insurance plans for product billing, the concern for confidentiality was also described, in particular when it came to explanation of benefits that could be sent to the policy-holders (i.e. parents) directly, thus breaching confidentiality for the adolescent.

"We're on our parents plans and so somehow I feel like the insurance would somehow let our [parents know]... they obviously would... if the teen didn't want to say they were on birth control, so I feel like most people would just prefer cash."

This concern is notable given assurances of confidentiality at the time an adolescent is at the pharmacy may not be sustained after they leave.

\subsubsection{Personal Benefits and Concerns}

Benefits to individuals that would be possible with pharmacist prescribing contraception were discussed, which included personal health outcomes, adolescent autonomy and also overcoming barriers that may exist with parental involvement. Personal health benefits included being able to access contraception and the possibility that it could increase control of their own health and outcomes.

"I think that for the most part it's a really good idea because l'm pregnant right now because ...I couldn't go to my parents to get birth control. ...If I had 
access to that I probably wouldn't be pregnant right now, which would be ideal."

Having the autonomy to make contraceptive decisions was an important attribute of having pharmacist prescribing of contraception that was described by participants.

Parental involvement being a potential barrier for access in the traditional care model was described and included not being able to obtain contraceptives at all. The pharmacist prescribing model was not presented as a way around parents, but more an option for access for adolescents in need of reliable pregnancy prevention methods.

\subsubsection{Social Impact}

In addition to individual benefits, the impact on larger society was discussed by participants and included the normalization of birth control use, safety concerns and improved outcomes with increased access to contraception. With increased access, and subsequent increased use, subjects described how that would normalize contraception use in society and be a positive impact on a larger community.

"I think that a lot of young women nowadays are a lot more open about their sexuality and not trying to hide what they're doing... so I think that if it's accessible to everyone it would be a positive change."

Older adolescents expressed concern over the safety of taking contraception correctly when it was prescribed by a pharmacist. Participants did not voice concerns regarding their own safety of taking hormonal contraception prescribed by a pharmacist, rather the safety concerns were often about other people using the contraception properly. However, benefits of pharmacist prescribing articulated by participants included improved accessibility to contraception for adolescents, especially younger ones, as well as possible long-term effects on teen pregnancy rates.

\subsection{Discussion}


Our study shows that amongst older adolescents in California that participated in this study, general support exists for pharmacist prescribing of contraception as a needed service and a role they felt pharmacists could serve. Participants acknowledged and appreciated relationships with their existing providers and the traditional care model, but were open to and interested in going directly to their pharmacist to meet their contraceptive needs for several noteworthy reasons. In addition, by expanding access via pharmacists, benefits to individuals and society as a whole could be experienced along with the normalization of contraception use. However, concerns about cost and confidentiality, both at the pharmacy and beyond, were noted by participants with this new model of care.

Pharmacy's prevalence in communities and expanded hours contributed to perceived convenience when this is widely implemented, as well as increased feelings of autonomy regarding contraceptive decisions and improved access for adolescents who did not feel that they could discuss contraception with their parents. However, concerns about cost and confidentiality were noted—not only while in the pharmacy, but also with respect to insurance billing. With young adults able to stay covered on their parents' health insurance plans through age twenty-five, confidentiality was a concern for older adolescents. California, in particular, has legal protections for sensitive service so that the confidentiality is maintained with insurance communications.

Although the product itself may be covered by insurance, visiting a pharmacist for counseling and the prescription may lead to a visit fee that is not currently covered by insurance plans. In addition, successful implementation will depend upon pharmacists obtaining the required training to provide this service, as well as private space to meet 
with patients and adequate time within their workflow to incorporate these patient visits and adequate counseling.

Given barriers to access for hormonal contraception, previous literature has examined pharmacists, clinicians and the general public's sentiments around pharmacist prescribing programs and found overall support. [14-23] A recent systematic review by Gonsalves et. al. in 2017 examined provision of sexual and reproductive health services within pharmacy settings and found similar support for such programs but also noted barriers to implementation of these programs.[24] Overall, the results of this study are consistent with existing literature, which demonstrate a strong trend that the public and health care community are supportive of pharmacist prescribing hormonal contraception and identify significant personal and societal benefits of this access model.

As legislation is passed and various states begin implementation, it is important that pharmacists are comfortable addressing adolescent needs. Furthermore, efforts to create youth-friendly spaces that assure confidentiality are vital in implementation efforts if access is truly to be improved. Furthermore, securing greater privacy protections for individuals insured as dependents and ensuring equitable reimbursement for patients with insurance benefits, regardless of prescribing provider type, are important factors to include for viable pharmacist prescribing.

There are some limitations to our study. First, the small sample size of adolescents in California who were recruited on social media and who almost all supported pharmacist prescribing, the results may not be generalizable to other populations. Also, information regarding adolescents who saw the advertisement but 
did not choose to participate in the survey is unknown. However, this is the only study to our knowledge that has utilized qualitative methods to examine adolescent's perspective of pharmacist prescribing of contraception. Second, due to limitations in the study protocol, adolescents younger than 18 years old were not interviewed. Thus, it is possible that interviews would have produced different themes if younger teens were also included. By using older teens, however, we did not need parental consent and obtained a more experienced perspective on how pharmacist prescribing of contraception would benefit not only adolescents of their age but also a younger group. Furthermore, nearly all study participants had past experience with contraception; therefore, they may feel more comfortable with pharmacists prescribing of contraceptives (especially the methods they are currently using) more so than a teenager who has never been on contraception.

Nonetheless, we feel that this study is an important addition to the literature and highlights the need to provide youth-friendly services to ensure pharmacist prescribing of non-long acting reversible contraception is successful at increasing access for adolescents and meeting their needs. With ongoing and pending changes to health insurance and contraception coverage as the future of the Affordable Care Act is challenged, pharmacist prescribing is an additional delivery model to facilitate access.

\section{Acknowledgements}

The authors would like to thank The National Campaign to Prevent Teen and Unplanned Pregnancy and the University of California San Diego Skaggs School of Pharmacy and Pharmaceutical Sciences for generously supporting this study. The authors acknowledge the contributions of Golsar Mirabolfathi, PharmD for help with proofreading transcripts, Ruth Manski, MPH for input on the interview guide, and Darci Miller, MBA for social media expertise. 
Funding: This work was supported by The National Campaign to Prevent Teen and Unplanned Pregnancy and the Skaggs Fund from the University of California, San Diego Skaggs School of Pharmacy \& Pharmaceutical Sciences

\section{REFERENCES}

[1] Finer LB, Zolna MR. Shifts in intended and unintended pregnancies in the United States, 2001-2008. Am J Public Health. 2014;104 Suppl 1:S43-8.

[2] Lindberg L, Santelli J, Desai S. Understanding the Decline in Adolescent Fertility in the United States, 2007\&\#x2013;2012. Journal of Adolescent Health.59:577-83.

[3] Bessett D, Prager J, Havard J, Murphy DJ, Agénor M, Foster AM. Barriers to Contraceptive Access after Health Care Reform: Experiences of Young Adults in Massachusetts. Women's Health Issues. 2015;25:91-6.

[4] Ralph L, Brindis CD. Access to reproductive healthcare for adolescents: establishing healthy behaviors at a critical juncture in the lifecourse. Current Opinion in Obstetrics \& Gynecology. 2010;22:369-74.

[5] Society for Adolescent M. Access to health care for adolescents and young adults. J Adolesc Health. 2004;35:342-4.

[6] Committee on Gynecologic Practice Long-Acting Reversible Contraception Working G. Committee Opinion No. 642: Increasing Access to Contraceptive Implants and Intrauterine Devices to Reduce Unintended Pregnancy. Obstetrics \& Gynecology. 2015;126:e44-8.

[7] The Best Intentions: Unintended Pregnancy and the Well-Being of Children and Families. Washington, DC: National Academy Press; 1995.

[8] Dehlendorf C, Rodriguez MI, Levy K, Borrero S, Steinauer J. Disparities in Family Planning. American Journal of Obstetrics \& Gynecology. 2010;202:214-20.

[9] Kilbourne AM, Switzer G, Hyman K, Crowley-Matoka M, Fine MJ. Advancing Health Disparities Research Within the Health Care System: A Conceptual Framework. American Journal of Public Health. 2006;96:2113-21.

[10] Curtis KM TN, Jatlaoui TC, et al. U.S. Medical Eligibility Criteria for Contraceptive Use, 2016. MMWR Recomm Rep 20162016.

[11] House Bill 2879. Oregon Legislative Assembly. In: Legislature O, editor.July 6, 2015.

[12] Senate Bill 16-135 Collaborative Pharmacy Practice Agreements. In: Legislature C, editor.June 6, 2016.

[13] Senate Bill No. 493-Chapter 469 Pharmacy Practice. California Senate; California Legislative Information. In: Legislature C, editor.Oct 1, 2013.

[14] Rafie S, Kelly S, Gray EK, Wong M, Gibbs S, Harper CC. Provider Opinions Regarding Expanding Access to Hormonal Contraception in Pharmacies. Women's Health Issues. 2016;26:153-60.

[15] Landau SC, Tapias MP, McGhee BT. Birth control within reach: a national survey on women's attitudes toward and interest in pharmacy access to hormonal contraception. Contraception. 2006;74:463-70.

[16] Landau S, Besinque K, Chung F, et al. Pharmacist interest in and attitudes toward direct pharmacy access to hormonal contraception in the United States. Journal of the American Pharmacists Association. 2009;49:43-50.

[17] Rafie S, Haycock M, Rafie S, Yen S, Harper CC. Direct pharmacy access to hormonal contraception: California physician and advanced practice clinician views. Contraception. 2012;86:687-93. 
[18] Rodriguez MI, McConnell KJ, Swartz J, Edelman AB. Pharmacist prescription of hormonal contraception in Oregon: Baseline knowledge and interest in provision. Journal of the American Pharmacists Association. 2016;56:521-6.

[19] Rafie S, El-Ibiary SY. Student pharmacist perspectives on providing pharmacy-access hormonal contraception services. J Am Pharm Assoc (2003). 2011;51:762-5.

[20] Rodriguez MI, Anderson L, Edelman AB. Prescription of Hormonal Contraception by Pharmacists in Oregon: Implementation of House Bill 2879. Obstet Gynecol. 2016;128:168-70.

[21] Grindlay K, Grossman D. Prescription birth control access among U.S. Women at risk of unintended pregnancy. Journal of Women's Health. 2016;25:249-54.

[22] Batra P, Aquilino ML, Farris KB. Pharmacy staff perceptions and selfreported behaviors related to providing contraceptive information and counseling. Journal of the American Pharmacists Association. 2015;55:481-7.

[23] Fakih S, Batra P, Gatny HH, Kusunoki Y, Barber JS, Farris KB. Young women's perceptions and experiences with contraception supply in community pharmacies. Journal of the American Pharmacists Association. 2015;55:255-64.

[24] Gonsalves L, Hindin MJ. Pharmacy provision of sexual and reproductive health commodities to young people: a systematic literature review and synthesis of the evidence. Contraception. 2017;95:33963. 
Table 1: Demographics of Participants ( $\mathrm{N}=30)$

\begin{tabular}{|c|c|}
\hline Demographic & $n(\%)$ \\
\hline \multicolumn{2}{|l|}{ Age } \\
\hline 18 years old & $15(50.0 \%)$ \\
\hline 19 years old & $15(50.0 \%)$ \\
\hline \multicolumn{2}{|l|}{ Race/Ethnicity } \\
\hline White & $11(36.7 \%)$ \\
\hline Black & $3(10.0 \%)$ \\
\hline Asian & $6(20 \%)$ \\
\hline Multiple & $3(10 \%)$ \\
\hline Hispanic & $9(30 \%)$ \\
\hline \multicolumn{2}{|l|}{ Education } \\
\hline Completed High School & $12(40.0 \%)$ \\
\hline Some College & $18(60.0 \%)$ \\
\hline \multicolumn{2}{|l|}{ Geographic Area* } \\
\hline Suburban & $19(63.3 \%)$ \\
\hline Urban & $7(23.3 \%)$ \\
\hline Rural & $3(10.0 \%)$ \\
\hline \multicolumn{2}{|l|}{ Past Contraceptives Used ${ }^{\star *}$} \\
\hline Condoms & $19(63.3 \%)$ \\
\hline Pills & $21(70.0 \%)$ \\
\hline Patch & $1(3.3 \%)$ \\
\hline Ring & $2(6.7 \%)$ \\
\hline Injectable & $1(3.3 \%)$ \\
\hline Emergency Contraception & $8(26.7 \%)$ \\
\hline Intrauterine Device & $1(3.3 \%)$ \\
\hline \multicolumn{2}{|l|}{ Past Contraception Source ${ }^{\star \star}$} \\
\hline Private Clinician Office & $8(26.7 \%)$ \\
\hline Clinic & $13(43.3 \%)$ \\
\hline Pharmacy & $16(53.3 \%)$ \\
\hline
\end{tabular}


Health Fair

Supported Pharmacists Prescribing Contraception

Yes
No
${ }^{*} n=29$
${ }^{* *}$ Participants endorsed all that applied

$1(3.3 \%)$

$29(97 \%)$

$1(3 \%)$ 
Table 2: Major and Sub-Themes with Example Quotes

\begin{tabular}{|c|c|}
\hline \multirow{2}{*}{\multicolumn{2}{|c|}{$\begin{array}{l}\text { Major Theme } \\
\text { Satisfaction and Challenges with Traditional Care Model }\end{array}$}} \\
\hline & \\
\hline $\begin{array}{r}\text { Satisfaction with Traditional } \\
\text { Providers }\end{array}$ & $\begin{array}{l}\text { "I feel like some people in my age group might prefer the } \\
\text { clinic just because it's a safe place that they know everyone } \\
\text { is here for the same reason." }\end{array}$ \\
\hline & $\begin{array}{l}\text { "I feel they have more knowledge about birth control so I can } \\
\text { trust them with the information that they're telling me and } \\
\text { because I just feel they're really confidential about things so if } \\
\text { I want to just keep it privately I can always go to them and } \\
\text { just ask them about the information about birth control." }\end{array}$ \\
\hline $\begin{array}{r}\text { Relationship with Current } \\
\text { Provider }\end{array}$ & $\begin{array}{l}\text { "I'm just really comfortable with my doctor, he makes me feel } \\
\text { at ease and he makes me feel like I can ask him anything } \\
\text { and expect an answer, a nonjudgmental answer." }\end{array}$ \\
\hline $\begin{array}{r}\text { Barriers with Traditional } \\
\text { Providers }\end{array}$ & $\begin{array}{l}\text { "I only get my birth control [as] a three-month supply so I } \\
\text { have to go back to my doctor every three months to get a } \\
\text { brand new prescription to take to the pharmacy. So it would } \\
\text { be a lot more convenient if I was able to go to the pharmacy } \\
\text { rather than having to see a doctor first." }\end{array}$ \\
\hline \multicolumn{2}{|l|}{ Pharmacy Environment } \\
\hline \multirow{4}{*}{$\begin{array}{r}\text { Pharmacy Confidentiality } \\
\text { Youth-Friendly } \\
\text { Environment/Space }\end{array}$} & $\begin{array}{l}\text { "I think making it available through drive-in pharmacies would } \\
\text { be good. Or also if there's a back room or something for } \\
\text { consultations instead of having to do it at the front desk in } \\
\text { front of everyone in the drug store." }\end{array}$ \\
\hline & $\begin{array}{l}\text { "The pills are okay because it was pretty confidential... } \\
\text { everyone just pretty much figured it was just like any other } \\
\text { medication. But the condoms ... I wish it could be more } \\
\text { confidential... I would try to do it alone and if someone } \\
\text { walked by I would just move a little over to the menstrual stuff } \\
\text { or something. Checking them out at the cashier was also a } \\
\text { little embarrassing." }\end{array}$ \\
\hline & $\begin{array}{l}\text { "Put signs up ... that teens are welcome that we have stuff } \\
\text { that you guys like. You guys can have access to birth control } \\
\text { in an easy way." }\end{array}$ \\
\hline & $\begin{array}{l}\text { "I feel if they had more advertisements directed towards } \\
\text { teens and kind of created an environment where people felt } \\
\text { that it was okay to come and then talk." }\end{array}$ \\
\hline $\begin{array}{l}\text { Pharmacist Knowledge and } \\
\text { Approachability }\end{array}$ & $\begin{array}{l}\text { "I would just say, just being open minded.. Because the } \\
\text { friendlier the pharmacist is, the more comfortable a girl feels } \\
\text { with their pharmacist." }\end{array}$ \\
\hline
\end{tabular}


Accessibility/Convenience

Accessibility/Convenience

\section{Birth Control Service Preferences}

"It's just so much easier to go to a pharmacist and there's just so many pharmacies around."

"They were really helpful and every time I go there, whenever I need questions [answered] they have a [pharmacist] to talk to you and if you need someone in Spanish, they also have people in Spanish available to talk to you and just explain how the prescription is to be used." a [Retail Chain] and it's probably a five-minute drive. Super easy, I could bike there.

Counseling "I think that education like sexual education for teens is definitely a necessity."

Personalized Service "It just has a lot of side effects and l'm afraid. So l'd have to go somewhere [to] see someone to tell me specific side effects and which one would be best for me and stuff like that."

"[Pharmacists] know all about the medications. So they just tell me... the side effects and also how [the medications] would work with your body and how it works."

Out of Pocket Expenses "I wouldn't mind paying, but right now I don't have the funds or money to be able to do that for myself."

"If it didn't affect the cost that I paid for my birth control, I would be totally unopposed to seeing a pharmacist."

Insurance Confidentiality

"They would always get the ... monthly insurance invoices just to know what services that were paid for. So that could be an awkward thing that some people might not feel comfortable with if they are like 'oh I don't want to tell my mom those kind of things."

\section{Personal Benefits and Concerns}

Personal Health Outcomes "The best is just knowing I'll be, I'm safe. You know? And now I don't have to worry about getting pregnant."

Autonomy of Teens "I think it's up for the teen to choose and especially if they do choose then they have access to it."

"I'd be in control of the situation if I initiated the question. It would make me feel more comfortable."

Parental Involvement "I think it's pretty great because me growing up I had strict parents so... having access to it without them finding out would have been very helpful." 
"I knew a lot of people who weren't allowed to use birth control due to their parents' religious beliefs, so a lot of girls weren't allowed to use birth control because their parents wouldn't fill their prescriptions. And so I think that if they were able to get their own from a pharmacist it would just be a lot easier on them."

\section{Social Impact}

Normalization of "I would feel like, 'okay, it's not just me that's coming here to Contraception Use get birth control. Everyone else does it too."

Safety Concerns "Those who are under 18 should let their parents know what they're taking just in case something happens to them and their parents know why like what's causing them to get hurt."

"If they didn't know how to take it properly or if they... didn't change it on time like the patch or the pill. Or if they overused it, say they take 3 birth control pills a day or two just to make sure, just to make sure they don't get pregnant."

"My biggest concern is that people would abuse it in the sense that maybe getting it and not necessarily using it themselves or trying to get it for other people because there's no way to verify who's actually taking the pills."

Improved Outcomes "I think that could help in a ... decrease in teen pregnancies, which is probably the biggest benefit. And just safety overall for the female herself and ... everyone because it could affect males too."

"Kids in high school need help especially since sexual education isn't exactly all that educational. So in terms of birth control, it would be good to be able to have that resource rather than having to go to their doctor." 